\title{
Comparison of Noninvasive Imaging Modalities for Stenosis Grading in Mesenteric Arteries
}

\author{
Vergleich nicht-invasiver Modalitäten zur Stenosegradbeurteilung \\ in Mesenterialarterien
}

Authors

Affiliations
P. J. Schaefer ${ }^{1}$, J. Pfarr ${ }^{1}$, J. Trentmann' ${ }^{1}$ A. M. Wulff' ${ }^{1}$ C. Langer ${ }^{2}$, M. Siggelkow ${ }^{3}$, J. Groß ${ }^{3}$, H. Knabe ${ }^{1}$, F. K. W. Schaefer ${ }^{1}$

Diagnostic Radiology, University Hospital Schleswig-Holstein Campus Kiel

${ }^{2}$ Cardiology and Angiology, University Hospital Schleswig-Holstein Campus Kiel

${ }^{3}$ Heart and Vascular Surgery, University Hospital Schleswig-Holstein Campus Kiel

\section{Key words \\ - arteries \\ - angiography \\ - CT angiography \\ - MR angiography \\ - ultrasound}

eingereicht 29.11 .2012

akzeptiert 10.2.2013

\section{Bibliography}

DOI http://dx.doi.org/

$10.1055 / \mathrm{s}-0033-1335212$

Published online: 05.06.2013

Fortschr Röntgenstr 2013; 185:

628-634 @ Georg Thieme

Verlag KG Stuttgart · New York . ISSN 1438-9029

\section{Correspondence \\ Dr. Philipp Jost Schaefer}

Diagnostic Radiology, University Hospital Schleswig-Holstein

Campus Kiel

Arnold-Heller-Strasse 3

(Haus 23)

24105 Kiel

Germany

Tel.: ++49/431/5974432

Fax: ++49/431/5973790

jp.schaefer@rad.uni-kiel.de

\section{Zusammenfassung}

$\nabla$

Ziel: Prospektive Analyse von Duplex-Sonografie, CTA und MRA versus DSA als Referenzstandard zur Stenosegradbeurteilung im Truncus coeliacus (TC) und Arteria mesenterica superior (AMS). Material und Methoden: Es wurden 52 Patienten eingeschlossen (mittleres Alter 71 Jahre). Die Bildqualität wurde beurteilt mit 1-unzureichend, 2-schlecht, 3-mäßig, 4-gut oder 5-exzellent. Stenosen wurden eingeteilt in die Grade $1(<25 \%)$, $2(25-<50 \%), 3(50-<75 \%)$ oder $4(>75 \%)$. Mittels zweiseitigen Chi-Quadrat-Tests wurde die Korrelation in der Stenosegradbeurteilung zwischen den Modalitäten bestimmt. Mittels gewichtetem Cohen's-kappa wurde das Korrelationsmaß berechnet. Für nicht-relevante versus relevante Stenosen (Schwellenwert 50\%) wurden Sensitivität, Spezifität, PPV, NPV und Genauigkeit ermittelt.

Ergebnisse: Die durchschnittliche Bildqualität für DSA/Duplex-Sonografie/CTA/MRA lag bei 3,8 $\pm 0,7 / 3,1 \pm 1,0 / 4,4 \pm 0,7 / 3,8 \pm 0,9$. Alle nicht-invasiven Modalitäten erreichten eine signifikante Korrelation in der Stenosegradbeurteilung für TC und AMS im Vergleich mit der DSA mit jeweils $\mathrm{p}<0,001$. Der gewichtete Cohen's-kappa betrug für Duplex-Sonografie/CTA/MRA für TC $0,94 / 0,93 / 0,74$ und für AMS 0,64/ 0,91/ 0,56. Die höchste Sensitivität/Spezifität/NPV/PPV/Genauigkeit erreichte die CTA mit 100\%/95\%/85\%/ $100 \% / 96 \%$ für den TC und mit na/98\%/na/100\%/ $98 \%$ für die AMS.

Schlussfolgerung: Bei bester Bildqualität erreichte die CTA das höchste Maß an Korrelation in der Stenosegradbeurteilung und bot die größte diagnostische Genauigkeit.

\section{Abstract \\ $\nabla$}

Objective: To prospectively analyze duplex sonography, CTA, and MRA with respect to stenosis grading of the celiac trunk (TC) and the superior mesenteric artery (SMA), with DSA as the reference.

Materials and Methods: 52 subjects were enrolled (mean age: 71 ). The image quality was graded: 1 -insufficient, 2-bad, 3-moderate, 4-good or 5-excellent. Stenosis was graded: $1(<25 \%), 2(25-<50 \%)$, $3(50-75 \%)$ or $4(75 \%)$. Two-sided chi-square tests were used to check for correlation of stenosis grading between modalities. The weighted Cohen's kappa was calculated to assess the strength of correlation. With a threshold of $50 \%$ for non-relevant stenosis vs. relevant stenosis, the sensitivity, specificity, PPV, NPV, and accuracy were calculated.

Results: The mean image quality was $3.8 \pm 0.7$, $3.1 \pm 1.0,4.4 \pm 0.7$, and $3.8 \pm 0.9$ for DSA, duplex sonography, CTA, and MRA, respectively. For both TC and SMA, stenosis grading reached a significant level of correlation between each noninvasive modality with DSA ( $p<0.001$, each). The weighted Cohen's kappa for duplex sonography/ CTA/MRA was $0.94 / 0.93 / 0.74$, respectively, for the TC and $0.64 / 0.91 / 0.56$, respectively, for the SMA. Highest sensitivity/specificity/NPV/PPV/ accuracy were found for CTA with $100 \% / 95 \% /$ $85 \% / 100 \% / 96 \%$ for the TC and with na/98\%/na/ $100 \% / 98 \%$, respectively, for the SMA.

Conclusion: CTA provided the best image quality, reached the highest level of agreement and significance in correlation in stenosis grading, and offered the best diagnostic accuracy. 


\section{Introduction}

\section{$\nabla$}

In patients with occlusive disease of the mesenteric arteries, precise imaging of the anatomic vascular tree is essential for diagnosis of mesenteric ischemia and exact planning of potential revascularization procedures [1]. Autopsy studies of an unselected population demonstrated mesenteric artery stenosis in up to $70 \%$ of cases [2]. The current reference standard for the definitive diagnosis of mesenteric artery stenosis is intra-arterial digital subtraction angiography (DSA) [3-5]. Because DSA is an invasive method involving exposure to ionizing radiation and nephrotoxic iodinated contrast agents, a noninvasive examination that has limited risks and can be performed easily on an outpatient basis is desirable. With duplex ultrasonography (US), computed tomography angiography (CTA) and magnetic resonance angiography (MRA), three different modalities are available for noninvasive imaging of mesenteric artery stenosis. Duplex US of mesenteric arteries is used primarily to detect relevant stenoses in the celiac trunk and the superior mesenteric artery (SMA) in patients with mesenteric ischemia [3]. Contrast agent-enhanced multi-detector CTA and contrast-enhanced (ce) 3D MRA are also widely used techniques to diagnose mesenteric ischemia [6-9]. No direct comparison of the different noninvasive imaging modalities to the reference standard DSA has been published for the mesenteric arteries, the celiac trunk and the SMA.

The population enrolled in the study underwent noninvasive duplex US, CTA and MRA and invasive DSA to evaluate the three noninvasive modalities versus the reference standard DSA with respect to stenosis grading in the celiac trunk and the SMA.

\section{Materials and Methods \\ $\nabla$}

\section{Study Design and Patient Population}

The study was approved by the Institutional Review Board. The study population was consecutively selected. Subjects considered eligible to be enrolled in the study were patients presenting with asymptomatic aortoiliac aneurysms or penetrating atherosclerotic ulcers that were to be treated by endovascular prosthesis placement. Respecting the rate of approximately $70 \%$ of mesenteric artery stenosis in an unselected population in the abovementioned autopsy study [2], we assumed a comparable prevalence of mesenteric artery stenosis in the elected patient population. The expected high prevalence should allow a competitive comparison of the three noninvasive methods, duplex US, CTA and MRA, versus the reference standard, DSA. Thus, our study is an anatomic investigation of mesenteric artery stenosis in the target vessels, the celiac trunk and the SMA.

In our hospital, patients with DSA-guided endovascular aortoiliac prosthesis placement undergo preinterventional CTA with arterial phase for planning purposes and postinterventional MRA with arterial and venous phase for follow-up. Therefore, imaging data of the aortoiliac and visceral arterial vasculature is available for those patients for DSA, CTA and MRA. According to the study protocol, the supplementary duplex US of the mesenteric arteries was performed in all enrolled patients within seven days of the endovascular prosthesis placement. So, no additional exposure of patients to ionizing radiation and to nephrotoxic contrast agents was necessary for study purposes. Written informed consent was obtained from all patients for all procedures.

Exclusion criteria were the patient (a) presenting with symptomatic/ruptured aortoiliac aneurysm or penetrating atheroscle- rotic ulcer; (b) not allowing successful prosthesis placement; (c) being unstable postinterventionally and requiring intensive care surveillance; $(d)$ having a history of life-threatening reaction to contrast agent; $(e)$ having a serum creatinine value greater than $132 \mu \mathrm{mol} / \mathrm{L}$; $(f)$ being a woman of child-bearing potential not using adequate contraception; $(g)$ being pregnant or lactating.

Within twelve months, 56 subjects were scanned to be included. Four subjects dropped out and were not enrolled because they had withdrawn consent before completion of all imaging modalities. Thus, a total of 52 subjects were included, with a male:female ratio of $43: 9$. The mean age was $71.2 \pm 10.8$ years (range: 44 to 87 years).

\section{Intra-arterial DSA}

Intra-arterial DSA was performed by experienced interventional radiologists with special skills in mesentericography and DSAguided major interventions. The DSA unit used was a Multistar T.O.P. (Siemens, Erlangen, Germany). A retrograde groin or transbrachial approach was chosen in each subject. A 5-F pigtail catheter (Nylex; Cordis, Johnson \& Johnson, Miami, FL, USA) was inserted, and its tip was placed at the origins of the celiac trunk and SMA. The image frequency was set to two per second. The contrast agent used was non-ionic iomeprol 300 (Imeron 300; Bracco, Milan, Italy). The volume of contrast agent administered was $20 \mathrm{~mL}$ per DSA sequence at an injection rate of $14 \mathrm{~mL} / \mathrm{sec}$. At least two projections in the anteroposterior, the right anterior oblique, the left anterior oblique or the lateral plane had to be obtained to collect valid imaging data for the evaluation of the mesenteric arteries. In selected cases $(n=7)$, super-selective angiography of the mesenteric arteries was performed ( $\bullet$ Fig. 1 ). In terms of suspected dynamic compression of the celiac trunk by the median arcuate ligament, angiograms in inspiration and expiration levels were obtained.

\section{Contrast-Enhanced MR Angiography}

$3 \mathrm{D}$ ceMRA was performed using a $1.5 \mathrm{~T}$ magnetom (Avanto; Siemens, Erlangen, Germany) with a phased-array coil. The settings of the $3 \mathrm{D}$ FLASH sequence for the ceMRA were $2.47 \mathrm{~s}$ repetition time, $0.9 \mathrm{~s}$ echo time, $15^{\circ}$ flip angle, $384 \times 384$ matrix (frequency $\times$ phase), $480 \mathrm{~mm}$ field-of-view, 6/8 rectangular field-of-view, $1.0 \mathrm{~mm}$ effective slice thickness, $17 \mathrm{~s}$ acquisition time. The contrast agent used was $1.0 \mathrm{M}$ gadobutrol (Gadovist; Bayer Healthcare, Berlin, Germany).

\section{Multi-Detector CT Angiography}

CTA was performed using a 64-row detector (Sensation; Siemens, Erlangen, Germany). The scan parameters for CTA were $0.6 \mathrm{~mm}$ collimation, 1.0 pitch, $100 \mathrm{kVp}, 150 \mathrm{mAs}$ tube current (care-dose adjusted), B25 $\mathrm{f}$ reconstruction kernel, $1.0 \mathrm{~mm}$ reconstruction increment. The contrast agent used was non-ionic iomeprol 350 (Imeron 350; Bracco, Milan, Italy).

\section{Duplex Ultrasonography}

Duplex US was performed by an independent radiologist with special skills in duplex scanning of mesenteric arteries. The ultrasound unit used was an Acuson S2000 (Siemens, Erlangen, Germany) with a 2 to $6 \mathrm{MHz}$ transducer. A combination of B-mode imaging, Doppler insonation and color-coded duplex scanning of the celiac trunk and SMA was obtained. 


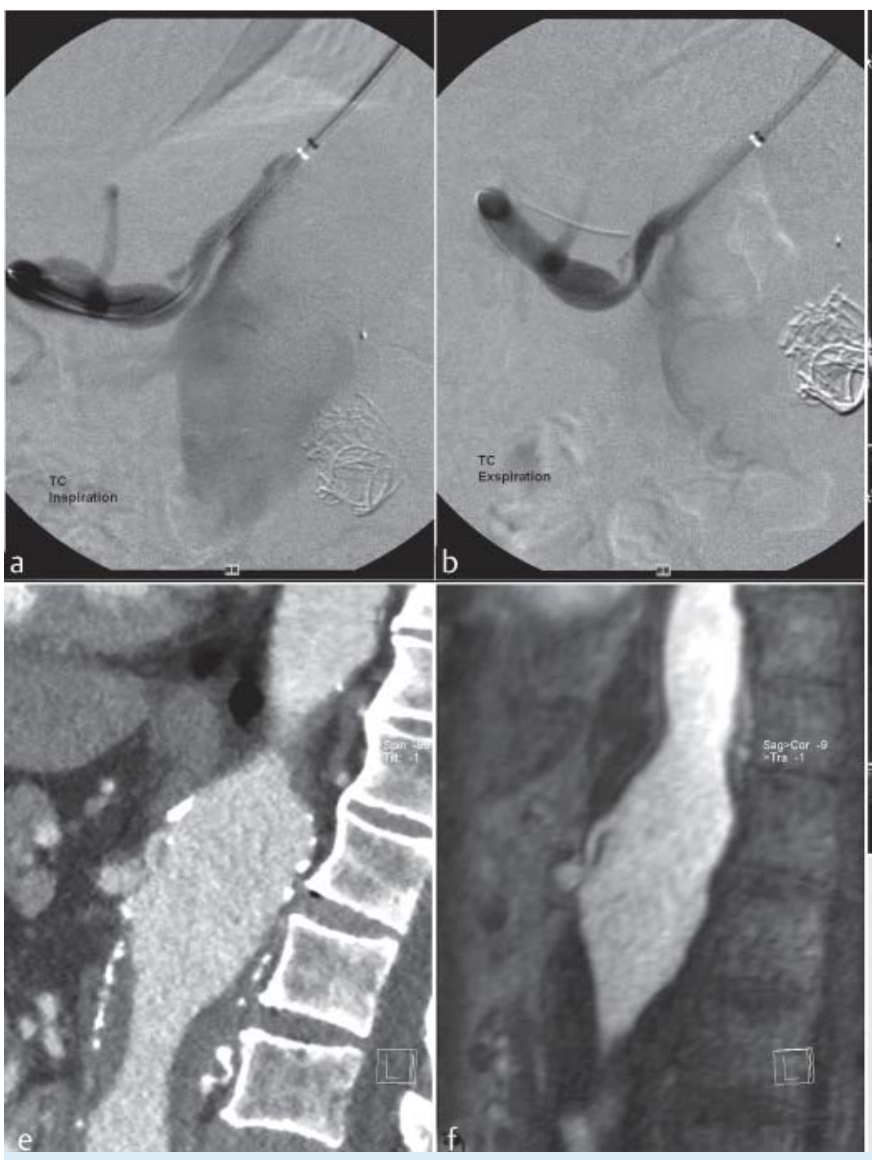

Fig. 1 67-year-old male patient with aortic and visceral artery aneurysm and relevant stenosis in the celiac trunk. DSA in $81^{\circ}$ left anterior oblique projection in inspiration $\mathbf{a}$ and expiration $\mathbf{b}$ revealed stenosis grade three $(50-75 \%)$ with additionally suspected small dissection. Assessment in duplex US was stenosis grade three $(50-75 \%)$ with peak systolic velocities of approximately $180 \mathrm{~cm} / \mathrm{sec}$ in inspiration c and of approximately $210 \mathrm{~cm} / \mathrm{sec}$ in expiration d. Multiplanar reformations of CTA $\mathbf{e}$ and MRA $\mathbf{f}$ in inspiration both revealed stenosis grade three ( $50-75 \%$ ) with additionally suspected small dissection corresponding to the DSA findings.

\section{Image Evaluation and Stenosis Grading}

The image evaluation and stenosis grading of duplex US were done during the US examination. The image data of DSA, CTA and MRA were anonymized, randomized and presented to two radiologists with a time span of four weeks between the evaluations of each modality. The two radiologists (twelve and eight years of experience reading DSA, CTA and MRA) read each of the modalities in consensus. The MRA data were presented as source images and the CTA data in $1 \mathrm{~mm}$ slice thickness, with the option of $3 \mathrm{D}$ post-processing on a dedicated workstation (Syngo; Siemens, Erlangen, Germany).

For stenosis grading, stenoses were classified according to a 4-grade scale ( $\bullet$ Table 1 ). To distinguish between non-relevant versus relevant stenosis, which was set as the primary endpoint, a 2-grade scale was calculated with grades one and two for non-relevant stenosis of less than $50 \%$, and with grades three and four for relevant stenosis of $50 \%$ or greater ( $\bullet$ Table 1 ). The image quality was evaluated according to a 5 -grade scale, with $1=$ insufficient, 2 =poor, 3 = moderate, 4 = good, 5 = excellent.

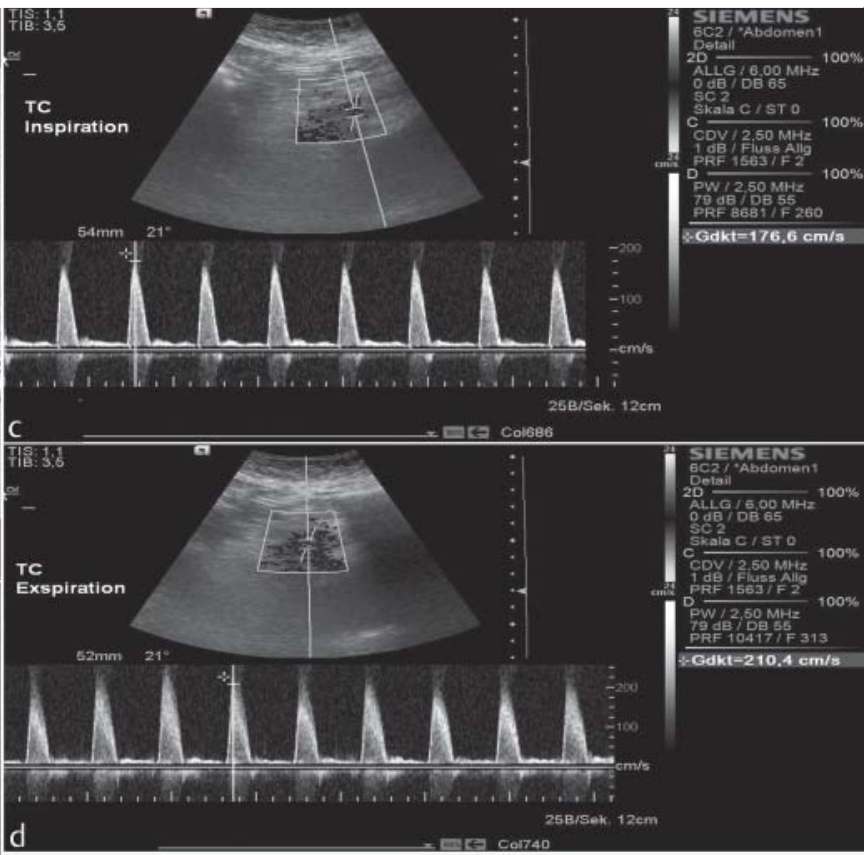

Abb. 1 67-jähriger männlicher Patient mit Aorten- und Viszeralarterienaneurysma mit relevanter Stenose im Truncus coeliacus. Die DSA in $81^{\circ}$ linksanteriorer Schrägprojektion in Inspiration a und Exspiration b zeigt Stenosegrad drei (50 - 75 \%) mit zusätzlich Verdacht auf geringfügige Dissektion. Die Beurteilung in der Duplex-Sonografie bestätigt Stenosegrad drei (50 $75 \%$ ) mit max. systolischer Geschwindigkeit von ca. $180 \mathrm{~cm} / \mathrm{s}$ in Inspiration c und von ca. $210 \mathrm{~cm} / \mathrm{s}$ in Exspiration d. Multiplanare Reformationen der CTA e und MRA $\mathbf{f}$ in Inspiration stellen jeweils Stenosegrad drei (50 - $75 \%$ ) mit zusätzlich Verdacht auf geringfügige Dissektion korrespondierend zur DSA dar.

Table 1 Stenosis grading for the target vessels, the celiac trunk and the superior mesenteric artery, according to a 4-grade scale and to a 2-grade scale, the latter to distinguish between non-relevant and relevant stenosis.

Tab. 1 Stenosegrade für die untersuchten Gefäße Truncus coeliacus und Arteria mesenterica superior gemäß 4-gradiger und 2-gradiger Skala, letztere zur Unterscheidung in nicht-relevante und relevante Stenosen.

\begin{tabular}{|llll|}
\hline grade & degree & grade & relevance \\
\hline 1 & no stenosis and stenosis $<25 \%$ & $1+2$ & non-relevant \\
\hline 2 & stenosis $\geq 25 \%$ and $<50 \%$ & & \\
\hline 3 & stenosis $\geq 50 \%$ and $<75 \%$ & $3+4$ & relevant \\
\hline 4 & stenosis $\geq 75 \%$ and occlusion & & \\
\hline
\end{tabular}

\section{Statistical Analysis}

The results for stenosis grading with the three noninvasive modalities were compared with the reference standard, DSA. For both the 4-grade scale and the 2-grade scale analysis, Pearson's chi-square tests were calculated to compare the degree of stenosis. A $p$-value 
Table 2 Cross table for stenosis classification according to the 4-grade scale in the celiac trunk and superior mesenteric artery to compare the noninvasive modalities duplex US, CTA and MRA versus DSA as the reference standard.

Tab. 2 Kreuztabelle für die Stenoseklassifizierung gemäß 4-gradiger Skala in Truncus coeliacus und Arteria mesenterica superior zum Vergleich der nicht-invasiven Modalitäten Duplex-Sonografie, CTA und MRA versus DSA als Referenzstandard.

\begin{tabular}{|c|c|c|c|c|c|c|c|c|c|}
\hline & & \multicolumn{8}{|l|}{ DSA } \\
\hline & & \multicolumn{4}{|c|}{ Celiac Trunk } & \multicolumn{4}{|c|}{ Superior Mesenteric Artery } \\
\hline & & $0-<25 \%$ & $\geq 25-<50 \%$ & $\geq 50-<75 \%$ & $\geq 75-100 \%$ & $0-<25 \%$ & $\geq 25-<50 \%$ & $\geq 50-<75 \%$ & $\geq 75-100 \%$ \\
\hline \multirow[t]{4}{*}{ Duplex US } & $0-<25 \%$ & 22 & 1 & 0 & 0 & 37 & 1 & 0 & 0 \\
\hline & $\geq 25-<50 \%$ & 1 & 8 & 1 & 0 & 2 & 2 & 1 & 0 \\
\hline & $\geq 50-<75 \%$ & 0 & 3 & 5 & 0 & 1 & 1 & 1 & 0 \\
\hline & $\geq 75-100 \%$ & 0 & 0 & 0 & 5 & 0 & 0 & 0 & 0 \\
\hline \multirow[t]{4}{*}{ CTA } & $0-<25 \%$ & 23 & 0 & 0 & 0 & 44 & 0 & 0 & 0 \\
\hline & $\geq 25-<50 \%$ & 3 & 11 & 0 & 0 & 1 & 3 & 0 & 0 \\
\hline & $\geq 50-<75 \%$ & 0 & 1 & 6 & 0 & 0 & 1 & 2 & 0 \\
\hline & $\geq 75-100 \%$ & 0 & 1 & 0 & 6 & 0 & 0 & 0 & 0 \\
\hline \multirow[t]{4}{*}{ MRA } & $0-<25 \%$ & 15 & 2 & 0 & 0 & 40 & 1 & 0 & 0 \\
\hline & $\geq 25-<50 \%$ & 7 & 7 & 1 & 0 & 3 & 1 & 0 & 0 \\
\hline & $\geq 50-<75 \%$ & 2 & 2 & 4 & 0 & 0 & 1 & 2 & 0 \\
\hline & $\geq 75-100 \%$ & 0 & 2 & 2 & 5 & 1 & 0 & 0 & 0 \\
\hline
\end{tabular}

Number $n$ of cases is presented.

of less than 0.05 was considered to indicate a significant level of correlation in stenosis grading. To prove concordance for stenosis grading among each noninvasive modality and DSA, the weighted Cohen's kappa coefficient was calculated for both the 4-grade scale and the 2-grade scale analysis. The sensitivity, specificity, positive and negative predictive values, and accuracy for detection of significant stenosis were calculated. To assess the level of correlation of the image quality among the evaluated modalities, the Kendall's tau b coefficient was calculated. A p-value of less than 0.05 was considered to indicate a significant level of correlation. As statistical software, SPSS (Version 2010; Chicago, IL, USA) was used.

\section{Results \\ $\nabla$}

48 subjects received all four imaging modalities. The reasons that partial imaging data for some subjects were not included in the analysis were: for duplex US, not offering sufficient data to assess the mesenteric arteries in six cases (eligible for analysis, $n=46$ ); for CTA, images lost in one case (eligible for analysis, $n=51$ ); for MRA, examination not possible due to a cardiac pacemaker in three cases (eligible for analysis, $\mathrm{n}=49$ ).

\section{Stenosis Grading on 4-Grade Scale}

The distribution of stenosis grading according to the 4-grade scale is presented in detail in 8 Table 2 . In the corresponding Pearson's chi-square test, the p-values reached level of significance concerning correlation in stenosis grading with $\mathrm{p}<0.001$ for all three noninvasive modalities for both the celiac trunk and SMA. Due to the calculated weighted Cohen's kappa coefficient, very high agreement for the celiac trunk was found for duplex US with 0.937 and for CTA with 0.929 , followed by MRA with 0.738 . The agreement for stenosis grading in the SMA was highest for CTA with 0.920 , followed by duplex US with 0.642 and MRA with 0.566 .

\section{Stenosis Grading on 2-Grade Scale}

In the 2-grade scale analysis for the primary endpoint, distinguishing between non-relevant stenosis of less than $50 \%$ (grades one and two) and relevant stenosis of $50 \%$ or greater (grades three and four), there were 13 relevant stenoses detected in the celiac trunk and 2 relevant stenoses detected in the SMA in DSA. The distribution of stenosis grading according to the 2-grade scale is presented in detail in $\bullet$ Table 3 . In the corresponding Pearson's chi-square test, the p-values reached level of significance concerning correlation in stenosis grading with $\mathrm{p}<0.001$ for all three noninvasive modalities for the celiac trunk, and with $\mathrm{p}=.011$ for duplex US, $\mathrm{p}=.009$ for CTA and $\mathrm{p}<0.001$ for MRA for the SMA. Due to the calculated weighted Cohen's kappa coefficient, the highest agreement for the celiac trunk was found for CTA with 0.897 , followed by duplex US with 0.771 and MRA with 0.661 . The agreement for stenosis grading in the SMA was highest again for CTA with 0.724 , followed by MRA with 0.647 and duplex US with 0.367 .

The sensitivity, specificity, positive predictive value and negative predictive value for identifying a relevant stenosis in the celiac trunk were highest for CTA with $100 \%, 95 \%, 86 \%$ and $100 \%$, respectively ( $\bullet$ Table 4 ). The diagnostic accuracy in the celiac trunk was best for CTA with $96 \%$, followed by duplex US and MRA with $91 \%$ and $86 \%$, respectively. With only a small number of relevant stenoses detected in the SMA, the specificity, negative predictive value and accuracy were highest for CTA with $98 \%, 100 \%$ and $98 \%$, respectively.

\section{Image Quality}

The image quality was classified as follows: quality for DSA, mean $3.8 \pm 0.7$ (insufficient, $\mathrm{n}=0$; poor; $\mathrm{n}=2$; moderate, $\mathrm{n}=16$; good, $\mathrm{n}=27$; excellent, $\mathrm{n}=7$ ); quality for duplex US, mean $3.1 \pm 1.0$ (insufficient, $\mathrm{n}=6$; poor; $\mathrm{n}=4$; moderate, $\mathrm{n}=24$; good, $\mathrm{n}=16$; excellent, $n=2$ ); quality for CTA, mean $4.4 \pm 0.7$ (insufficient, $n=0$; poor; $n=0$; moderate, $n=5$; good, $n=21$; excellent, $n=25$; drop out, $\mathrm{n}=1$ ); quality for MRA, mean $3.8 \pm 0.9$ (insufficient, $\mathrm{n}=0$; 
Table 3 Cross table for stenosis classification according to the 2 -grade scale for non-relevant stenosis ( $<50 \%$ ) versus relevant ( $\geq 50 \%$ ) stenosis in the celiac trunk and superior mesenteric artery to compare the noninvasive modalities duplex US, CTA and MRA versus DSA as the reference standard.

Tab. 3 Kreuztabelle für die Stenoseklassifizierung gemäß 2-gradiger Skala für nicht-relevante ( $<50 \%$ ) versus relevante ( $\geq 50$ \%) Stenosen in Truncus coeliacus und Arteria mesenterica superior zum Vergleich der nicht-invasiven Modalitäten Duplex-Sonografie, CTA und MRA versus DSA als Referenzstandard.

\begin{tabular}{|c|c|c|c|c|c|}
\hline & & \multicolumn{4}{|l|}{ DSA } \\
\hline & & \multicolumn{2}{|c|}{ Celiac Trunk } & \multicolumn{2}{|c|}{ Superior Mesenteric Artery } \\
\hline & & $0-<50 \%$ & $\geq 50-100 \%$ & $0-<50 \%$ & $\geq 50-100 \%$ \\
\hline \multirow[t]{2}{*}{ Duplex US } & $0-<50 \%$ & 32 & 1 & 42 & 1 \\
\hline & $\geq 50-100 \%$ & 3 & 10 & 2 & 1 \\
\hline \multirow[t]{2}{*}{ CTA } & $0-<50 \%$ & 37 & 0 & 48 & 0 \\
\hline & $\geq 50-100 \%$ & 2 & 12 & 1 & 2 \\
\hline \multirow[t]{2}{*}{ MRA } & $0-<50 \%$ & 31 & 1 & 45 & 0 \\
\hline & $\geq 50-100 \%$ & 6 & 11 & 2 & 2 \\
\hline
\end{tabular}

Number $n$ of cases is presented.

Table 4 Sensitivity, specificity, positive predictive value (PPV), negative predictive value (NPV) and accuracy for detecting relevant stenoses in the celiac trunk and the superior mesenteric artery.

Tab. 4 Sensitivität, Spezifität, positive prädiktiver Wert (PPV), negative prädiktiver Wert (NPV) und Genauigkeit zur Detektion relevanter Stenosen in Truncus coeliacus und Arteria mesenterica superior.

\begin{tabular}{|c|c|c|c|}
\hline & & $\begin{array}{l}\text { Celiac } \\
\text { Trunk }\end{array}$ & $\begin{array}{l}\text { Superior Mesenteric } \\
\text { Artery }\end{array}$ \\
\hline \multirow[t]{3}{*}{ sensitivity \% } & Duplex US & 91 & n.a. \\
\hline & CTA & 100 & n.a. \\
\hline & MRA & 92 & n.a. \\
\hline \multirow[t]{3}{*}{ specificity \% } & Duplex US & 91 & 96 \\
\hline & CTA & 95 & 98 \\
\hline & MRA & 84 & 96 \\
\hline \multirow[t]{3}{*}{ PPV \% } & Duplex US & 77 & n.a. \\
\hline & CTA & 86 & n.a. \\
\hline & MRA & 65 & n.a. \\
\hline \multirow[t]{3}{*}{ NPV \% } & Duplex US & 97 & 98 \\
\hline & CTA & 100 & 100 \\
\hline & MRA & 97 & 100 \\
\hline \multirow[t]{3}{*}{ accuracy \% } & Duplex US & 91 & 93 \\
\hline & CTA & 96 & 98 \\
\hline & MRA & 86 & 96 \\
\hline
\end{tabular}

Due to small numbers, the values for sensitivity and PPV in the superior mesenteric artery were not calculated.

poor; $n=4$; moderate, $n=11$; good, $n=24$; excellent, $n=10$; drop out, $\mathrm{n}=3$ ). Representative imaging of a case is shown in $\bullet$ Fig. 1 . The Kendall's tau b coefficient was 0.266 between duplex US and DSA with $\mathrm{p}=.031$, indicating a significant correlation of the image qualities. The Kendall's tau b coefficients were $0.189(\mathrm{p}=.142)$ between CTA and DSA and $0.045(\mathrm{p}=.724)$ between MRA and DSA, indicating no significant correlation of the image qualities.

\section{Discussion}

$\nabla$

Noninvasive duplex US, CTA and MRA are frequently used techniques for diagnosing mesenteric ischemia, and, in this context, their primary clinical application is to identify stenoses in the celiac trunk and the SMA that may be associated with the clinical findings $[3,6,7,10]$. With a positive duplex US study, additional imaging by usually CTA or MRA is required for confirmation prior to any mesenteric artery reconstruction [3]. Intra-arterial DSA is deemed the reference standard for the investigation of mesenteric arteries, and offers the highest spatial resolution and finest image details, which is essential for reliable grading of mesenteric artery stenosis $[3,8,11]$.

In our study, all three noninvasive modalities reached level of significance concerning correlation in stenosis grading with $p<0.001$ for the celiac trunk and with $p$ between $p=.011$ and $\mathrm{p}<0.001$ for the SMA. Thus, with the decision for CTA and MRA by two-reader consensus and for duplex US by the independent radiologist, the three modalities offered reliable results for stenosis grading in comparison to the reference standard, DSA. The highest agreement rate according to the weighted Cohen's kappa coefficient was found for CTA for both mesenteric arteries. The coefficients ranged from 0.724 for the SMA in the 2-grade scale analysis to 0.929 for the celiac trunk in the 4-grade scale analysis, indicating high agreement if compared to DSA. The agreement was also high with a coefficient of 0.937 for duplex US in the assessment of the celiac trunk in the 4-grade scale analysis. All other calculated Cohen's kappa coefficients remained lower with ranges from 0.367 to 0.771 for duplex US and from 0.566 to 0.738 for MRA in the corresponding analyses of the two mesenteric arteries. With regard to sensitivity, specificity, positive and negative predictive value and diagnostic accuracy for identifying a relevant stenosis, CTA provided the highest values for both vessels. These results indicating CTA as the best noninvasive modality are supported by the best overall image quality judged good to almost excellent with a mean of 4.4.

As stated by Shih and Hagspiel, no direct comparison of MRA and CTA for mesenteric artery stenosis has been published [6], and as there is no comparison of all three noninvasive modalities versus DSA as the reference standard available in the literature, our study offers the first comprehensive comparative results for all modalities in the evaluation of mesenteric artery stenosis. Corresponding to Bhatti et al. [12] who found CTA superior to MRA in renal arteries, our data indicate the superiority of CTA over MRA and duplex US in the two mesenteric arteries. Loewe et al. refer to the outstanding role of CTA as a safe, robust and reproducible modality for diagnosing diseased abdominal arteries, and they rated the broad majority of their evaluated abdominal arteries as of good or excellent image quality [13]. We found CTA to offer the best image quality among the four assessed modalities, rated 4.4 as also good to excellent imaging. In our comparison, image quality was ranked lowest with 3.1 (i.e., moderate) for du- 
plex US, and was estimated equally with 3.8 (i. e., almost good) for both MRA and DSA. There was a significant correlation for the image quality between the reference DSA and the tested modalities only for duplex US, but not for CTA and MRA. As all four modalities are technically completely different in terms of image data acquisition, these results seem acceptable. We do not consider the existence or non-existence of a significant correlation as having a relevant impact on the stenosis grading in the target vessels.

Though DSA offers the highest spatial resolution $[3,8,11]$, its image quality is user-dependent and may be influenced by superselective angiography in selected cases ( $\bullet$ Fig. 1). As DSA allows only catheter based angiography and is thus limited to vascular diagnoses, all tested noninvasive modalities may provide additional information regarding tissue and organs surrounding the mesenteric arteries and thus expand the diagnostic field [6-8, 14-17]. Especially in patients with acute mesenteric ischemia, CTA is considered the first-line imaging method [16-22]. With the high prevalence of mesenteric artery stenosis of up to $70 \%$ [2], an accurate assessment of a potential mesenteric artery stenosis is essential concerning the diagnosis of acute mesenteric ischemia. Although we performed an anatomic investigation of the stenosis degree and did not focus on patients with acute mesenteric ischemia, our data providing the best results for CTA support that statement. As noted elsewhere, advanced CT scanners with improved spatial and temporal resolution may visualize the mesenteric vasculature with an image resolution comparable to that of DSA $[8,23,24]$. So, CTA seems to have the potential to become the reference imaging modality for mesenteric vasculature [25].

There are several reports describing MRA with its high-quality imaging as a suitable technique for mesenteric ischemia $[6,7$, $10,25]$. Our data proved MRA to be a reliable imaging modality for the grading of mesenteric artery stenosis. However, in comparison to duplex US and CTA, its results remained below these two competitive modalities. MRA may be favored over CTA since the patient is not exposed to ionizing radiation. However, as Shih et al. state [10], we see limitations for MRA due to the lower spatial resolution, longer acquisition times and potential stent-induced artifacts, which may prevent a sufficient stenosis classification.

In a former study, Moneta et al. demonstrated the feasibility of duplex US in the mesenteric arteries, the celiac trunk and the SMA [14]. For detecting relevant stenosis with a threshold of $70 \%$, they reported a sensitivity, specificity, and accuracy of $87 \%, 80 \%$, and $82 \%$, respectively, for the celiac trunk and $92 \%, 96 \%$, and $96 \%$, respectively, for the SMA. Zwolak et al. used a $50 \%$ threshold for relevant stenosis, and they achieved a sensitivity, specificity, and accuracy of $93 \%, 100 \%$, and $95 \%$, respectively, for the celiac trunk and $90 \%, 91 \%$, and $91 \%$, respectively, for the SMA [26]. Setting the threshold for relevant stenosis also at $50 \%$, we found comparable numbers in the abovementioned ranges for the celiac trunk with $91 \%$ for the sensitivity, specificity, and accuracy, and for the SMA with $96 \%$ for the specificity and $93 \%$ for the accuracy. Thus, our data for duplex US are similar to that reported in the literature before, but remain below those for CTA in our comprehensive multimodality study.

There are several limitations in our study that should be addressed: First, the unselected study population focusing on subjects without clinical symptoms of mesenteric ischemia allowed an anatomic investigation of mesenteric artery stenosis. Second, the low number of relevant stenoses in the SMA influenced the statistical analysis with a decreasing effect on the interpretability of the corresponding results. Third, the fashion of image acquisition and interpretation of each modality: consensus read for CTA and MRA images, performance and interpretation of duplex US by an independent radiologist, performance of DSA by an independent radiologist and interpretation in consensus. This scenario created a bias toward noninvasive CTA and MRA by offering the greatest objectivity.

In summary, the correlation levels achieved for the classification of stenosis with findings in the noninvasive modalities, duplex US, CTA and MRA, compared with those for classification with findings in DSA reached significance for both the celiac trunk and the SMA. Thus, all three modalities offered reliable results for stenosis grading in these two mesenteric arteries, with the limitation of an anatomic investigation by enrolling an unselected study population. Nevertheless, our results offer a comprehensive comparison of all noninvasive modalities versus the reference standard, DSA, for the grading of mesenteric artery stenosis. Based on our results for correlation and agreement in stenosis grading of the celiac trunk and the SMA, we found CTA to have priority over MRA and duplex US, when compared to DSA as the reference standard.

\section{References}

1 Schaefer PJ, Boudghene FP, Brambs HJ et al. Abdominal and iliac arterial stenosis: comparative double-blinded randomized study of diagnostic accuracy of 3D MR angiography with gadodiamide or gadopentetate dimeglumine. Radiology 2006; 238: 827-840

2 Zelenock GB, Graham LM, Whitehouse WM Jr et al. Splanchnic arteriosclerotic disease and intestinal angina. Arch Surg 1980; 115: 497-501

3 Mitchell EL, Moneta GL. Mesenteric duplex scanning. Perspect Vasc Surg Endovasc Ther 2006; 18: 175-183

4 Schaefer PJ, Schaefer FK, Hinrichsen $H$ et al. Stent placement with the monorail technique for treatment of mesenteric artery stenosis. J Vasc Interv Radiol 2006; 17: 637-643

5 Minko P, Groesdonk H, Stroeder J et al. A scoring system for the assessment of angiographic findings in non-occlusive mesenteric ischemia (NOMI). Fortschr Röntgenstr 2012; 184: 805-809

6 Shih MC, Hagspiel KD. CTA and MRA in mesenteric ischemia: part 1, role in diagnosis and differential diagnosis. Am J Roentgenol Am J Roentgenol 2007; 188: $452-461$

7 Hagspiel KD, Leung DA, Angle JF et al. MR angiography of the mesenteric vasculature. Radiol Clin North Am 2002; 40: 867-886

8 Menke J. Diagnostic accuracy of multidetector CT in acute mesenteric ischemia: systematic review and meta-analysis. Radiology 2010; 256: $93-101$

9 Schwartz CA, Haage P, Hohl C. Experimentelle Frühdiagnostik der akuten mesenterialen Ischämie mittels diffusionsgewichteter MRT (DWI) und paralleler Bildgebung. Fortschr Röntgenstr 2012; 184: 520-526

10 Shih MC, Angle JF, Leung DA et al. CTA and MRA in mesenteric ischemia: part 2, normal findings and complications after surgical and endovascular treatment. Am J Roentgenol Am J Roentgenol 2007; 188: 462 471

11 Schaefer PJ, Schaefer FK, Mueller-Huelsbeck S et al. Chronic mesenteric ischemia: stenting of mesenteric arteries. Abdom Imaging 2007; 32: 304-309

12 Bhatti AA, Chugati A, Haslam P et al. Prospective study comparing three-dimensional computed tomography and magnetic resonance imaging for evaluating the renal vascular anatomy in potential living renal donors. BJU Int 2005; 96: $1105-1108$

13 Loewe C, Becker CR, Berletti R et al. 64-slice CT angiography of the abdominal aorta and abdominal arteries: comparison of the diagnostic efficacy of iobitridol $350 \mathrm{mgl} / \mathrm{ml}$ versus iomeprol $400 \mathrm{mgl} / \mathrm{ml}$ in a prospective, randomised, double-blind multi-centre trial. Eur Radiol 2010; 20: $572-583$

14 Moneta GL, Lee RW, Yeager RA et al. Mesenteric duplex scanning: a blinded prospective study. J Vasc Surg 1993; 17: 79-86

15 Klein HM, Lensing R, Klosterhalfen B et al. Diagnostic imaging of mesenteric infarction. Radiology 1995; 197: 79-82 
16 Kirkpatrick ID, Kroeker MA, Greenberg HM. Biphasic CT with mesenteric CT angiography in the evaluation of acute mesenteric ischemia: initial experience. Radiology 2003; 229: 91 - 98

17 Ferro C, Rossi UG, Seitun $S$ et al. Endovascular treatment of totally occluded superior mesenteric artery by retrograde crossing via the Villemin arcade. Cardiovasc Intervent Radiol 2012; DOI: 10.1007/s00270012-0469-y

18 Wiesner W, Hauser A, Steinbrich W. Accuracy of multidetector row computed tomography for the diagnosis of acute bowel ischemia in a non-selected study population. Eur Radiol 2004; 14: 2347-2356

19 Aschoff AJ, Stuber G, Becker BW et al. Evaluation of acute mesenteric ischemia: accuracy of biphasic mesenteric multidetector $\mathrm{CT}$ angiography. Abdom Imaging 2009; 34: 345-357

20 Ofer A, Abadi S, Nitecki $S$ et al. Multidetector CT angiography in the evaluation of acute mesenteric ischemia. Eur Radiol 2009; 19: 24-39

21 Akyildiz H, Akcan A, Oztürk A et al. The correlation of the D-dimer test and biphasic computed tomography with mesenteric computed tomo- graphy angiography in the diagnosis of acute mesenteric ischemia. Am J Surg 2009; 197: 429-433

22 Gagniere J, Favrolt G, Alfidja A et al. Acute thrombotic mesenteric ischemia: primary endovascular treatment in eight patients. Cardiovasc Intervent Radiol 2011; 34: 942 -948

23 Kandel S, Kloeters C, Meyer H et al. Whole-organ perfusion of the pancreas using dynamic volume $\mathrm{CT}$ in patients with primary pancreas carcinoma: acquisition technique, post-processing and initial results. Eur Radiol 2009; 19: 2641 - 2646

24 Heiss $P$, Wrede CE, Hamer OW et al. Multidetector computed tomography mesentericography for the diagnosis of obscure gastrointestinal bleeding. Fortschr Röntgenstr 2011; 183: 37-46

25 Chow $L C$, Chan FP, Li KC. A comprehensive approach to MR imaging of mesenteric ischemia. Abdom Imaging 2002; 27: 507-516

26 Zwolak RM, Fillinger MF, Walsh DB et al. Mesenteric and celiac duplex scanning: a validation study. J Vasc Surg 1998; 27: 1078-1087 